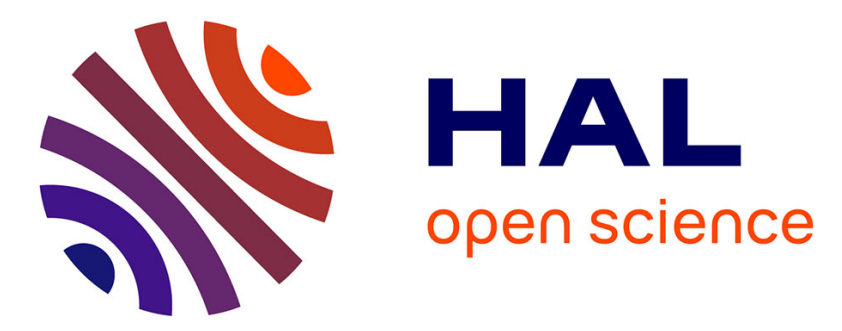

\title{
Catalytic glycosylation of glucose with alkyl alcohols over sulfonated mesoporous carbons
}

\author{
Wahiba Ghezali Ramdani, Ayman Karam, Karine de Oliveira Vigier, \\ Sébastien Rio, Anne Ponchel, François Jerome
}

\section{To cite this version:}

Wahiba Ghezali Ramdani, Ayman Karam, Karine de Oliveira Vigier, Sébastien Rio, Anne Ponchel, et al.. Catalytic glycosylation of glucose with alkyl alcohols over sulfonated mesoporous carbons. Journal of Molecular Catalysis, 2019, 468, pp.125-129. 10.1016/j.mcat.2019.02.016 . hal-02058724

\section{HAL Id: hal-02058724 \\ https://hal.science/hal-02058724}

Submitted on 22 Oct 2021

HAL is a multi-disciplinary open access archive for the deposit and dissemination of scientific research documents, whether they are published or not. The documents may come from teaching and research institutions in France or abroad, or from public or private research centers.
L'archive ouverte pluridisciplinaire HAL, est destinée au dépôt et à la diffusion de documents scientifiques de niveau recherche, publiés ou non, émanant des établissements d'enseignement et de recherche français ou étrangers, des laboratoires publics ou privés.

\section{(ㅇ)(1) $\$$}

Distributed under a Creative Commons Attribution - NonCommerciall 4.0 International 


\title{
Catalytic glycosylation of glucose with alkyl alcohols over sulfonated
}

\section{mesoporous carbons}

\author{
Wahiba Ghezali Ramdani, ${ }^{a}$ Ayman Karam, ${ }^{a}$ Karine De Oliveira Vigier, ${ }^{a}$ Sébastien Rio, ${ }^{\mathrm{b}}$ Anne \\ Ponchel, ${ }^{* \mathrm{~b}}$ and François Jérôme*a \\ ${ }^{a}$ Institut de Chimie des Milieux et Matériaux de Poitiers, CNRS/Université de Poitiers, 1 rue Marcel Doré, ENSIP \\ Bat B1, 86073 Poitiers, France. Email : francois.jerome@univ-poitiers.fr \\ ${ }^{b}$ Univ. Artois, CNRS, Centrale Lille, ENSCL, Univ. Lille, UMR 8181, Unité de Catalyse et de Chimie du Solide \\ (UCCS), F-62300 Lens, France.Email : anne.ponchel@univ-artois.fr
}

\begin{abstract}
Herein we investigated the catalytic performances of sulfonated mesoporous carbons in the glycosylation of carbohydrates with alkyl alcohols. Catalytic performances were compared to common solid acid catalysts previously reported for this reaction. Under optimized conditions, the targeted alkyl glycosides were obtained in $85 \%$ yield, together with a turn over frequency and a space time yield higher than those of the best heterogeneous catalysts reported so far in such reaction. Furthermore, the presence of mesoporous channels significantly lowered the deactivation rate of the catalyst in comparison to a non-porous sulfonated carbon.
\end{abstract}

Keywords: Biomass, Catalysis, Carbohydrates, Glycosylation, Mesoporous carbon. 


\section{Introduction}

With the exponential growth of the world population, and our concerns about climate changing, the chemical industry needs to produce always more and better from resources that are declining or becoming less and less accessible. In this context, carbohydrates represent a huge reservoir of renewable carbon from which a myriad of chemicals can be theoretically produced.[1-11] The implementation of sugar-based processes on a large scale is far from being an easy task and it requires scientists to overcome scientific and technological bottlenecks. For instance, carbohydrates tend to form tar-like materials, also commonly named humins, which not only decreases the overall selectivity of the catalytic process but also leads to a severe deactivation of solid catalysts.[12-13] As a consequence, the space time yield of sugar-based processes are often too low to be competitive with petrochemical processes, for which chemistry has developed very efficient technologies over more than 70 years.

The catalytic Fischer glycosylation of glucose with fatty alcohols is one of the important sugarbased reactions deployed at an industrial scale.[14-21] This reaction is catalyzed by sulfuric acid and yields amphiphilic alkyl glycosides (AAG) that are valuable biosurfactants, with current applications in the cosmetic and detergence industries. The price of AAG is about $1.5-2 € / \mathrm{kg}$, which is still too high to compete with fossil derived surfactants exhibiting similar performances. Optimization of the catalytic Fisher glycosylation reaction is one of the options to decrease the production cost of AAG. In particular, the replacement of $\mathrm{H}_{2} \mathrm{SO}_{4}$ by robust, active and recyclable solid acid catalysts is a possible strategy. Beside the intrinsic catalytic performances of solid acids, the absence of neutralization step at the end of the reaction and the easiness in recovery/recycling of solid catalysts represent additional advantages over $\mathrm{H}_{2} \mathrm{SO}_{4}$.

From the view point of catalysis, the direct glycosylation of unprotected carbohydrates with fatty alcohols is a difficult reaction. In particular, improving the catalyst activity is essential in 
order to assure that the glycosylation rate of carbohydrates is higher than their thermal degradation rate to humins, as above mentioned these tar-like materials leading to a rapid deactivation of catalysts. In the field of heterogeneous catalysis, this reaction is even more complex to kinetically control because carbohydrates and fatty alcohols are bulky substrates, which restrict to some extent, their accessibility to the grafted or anchored catalytic sites, thus reducing the catalyst activity.

With these criteria in mind, microporous catalysts and gel-type resins were previously reported. Two catalytic strategies can be distinguished in the current literature. The first option consists in synthesizing AAG by the direct catalytic Fischer glycosylation of glucose with fatty alcohols under biphasic conditions. In this case, zeolite $\mathrm{H}-\mathrm{BEA}(\mathrm{Si} / \mathrm{Al}=25),[22] \mathrm{ZnFe}_{2} \mathrm{O}_{4}$ supported on $\mathrm{ZrO}_{2}$,[23] $\mathrm{H}_{2} \mathrm{SO}_{4} / \mathrm{SiO}_{2},[24,25]$ polyvinyl bound tri- and disulfonate ethylamine chloride[26] and Aquivion PFSA [27] have been previously investigated and good to excellent yields were claimed. Cellulose, and even lignocellulosic biomass, were also successfully employed as a source of glucose in the synthesis of AAGs through glycosylation reaction.[28] In order to overcome the low miscibility of carbohydrates with fatty alcohols, a second strategy was explored in the literature. It consists in the transglycosylation of pre-synthesized methyl- or butylglycosides with fatty alcohols. Catalysts of the type Amberlyst-15, Nafion SAC-13, zeolite ITQ-2, sulfonated carbons, sulfonated graphene oxides and heteropolyacids were typically used in such approach [28d, 29]. Even though the catalytic transglycosylation of methyl/butylglycosides with fatty alcohols generally led to catalytic reactions with higher space time yields than the direct glycosylation of glucose with fatty alcohols, it has however the main drawback of requiring an extra synthetic step. One should however mention that, in some cases, 
the glycosylation and transglycosylation reactions were advantageously combined in a successive way in a single reactor, thus avoiding intermediate purification.[28d]

In all these examples, the catalyst activity is depending on (i) the strength of acid sites (Bronsted or Lewis) and (ii) the accessibility of acid sites, which is often improved by the presence of micropores or by the ability of catalysts to swell into the reaction media. The release of water as a co-product and the formation of tar-like materials impact, to a more or less extent, the long term stability of catalyst (catalyst coking, surface hydrolysis, etc.). Whatever the catalytic routes (glycosylation $v s$ transglycosylation), good results were generally claimed in terms of yield and selectivity but the stability, the recyclability and the space time yields of these solid catalysts needs to be further improved to be more competitive with $\mathrm{H}_{2} \mathrm{SO}_{4}$, the reference catalyst used at the industrial scale for such reaction.[14]

In the field of heterogeneous catalysis applied to biomass, carbon-based catalysts are attracting growing interest.[30-39] The improved stability of carbon materials in the presence of water (common co-product or solvent in carbohydrate chemistry), their ease of surface functionalization, the possibility to tune their surface polarity and prepare them at a nanoscale represent important features which were previously taken as advantages in the catalytic conversion of carbohydrates [40-41]. From all these data, it occurred to us that sulfonated mesoporous carbons could be promising catalysts for the direct catalytic glycosylation of glucose with fatty alcohols, the presence of mesopores being expected to dramatically facilitate the diffusion of carbohydrates within the catalyst backbone while the carbonaceous skeleton should confer to the catalyst a greater stability in the presence of water than metal oxides for instance. As recently reviewed by Doustkhah et al., sulfonated carbons have been used as solid acid catalysts in a wide range of reactions such as acetalization, C-C bond couplings, Fries and 
Beckman rearrangement, etc [42]. To the best of our knowledge, the catalytic activity of sulfonated mesoporous carbons has never been reported in the direct Fisher glycosylation of carbohydrates with fatty alcohols, although this family of catalyst gathers the main criteria to be efficient in such reaction. Mesoporous carbons are typically prepared by the so-called hardtemplating synthesis. The mesoporous carbons are thus the negative replica of an inorganic hard template used as mold. Typically, cubically mesoporous MCM-48 aluminosilicate or mesoporous silica such as 3D cubic cage-like SBA-1 and 2D hexagonal SBA-15 were used as an inorganic template and afford mesoporous carbons referred as CMK-1, CMK-2 and CMK-3, respectively $[43,44]$. Then, these mesoporous carbons can be sulfonated according to different strategies, including sultone, sulfuric acid, etc [42].

In this communication, we thus investigate the catalytic performances of various sulfonated mesoporous carbons in the direct glycosylation of glucose with $n$-dodecanol. Sulfonated mesoporous carbons were then benchmarked to previously reported solid acid catalysts, and also from various carbohydrates and alkyl alcohols, to assess their potential but also their limitations.

\section{Experimental section}

In a typical procedure, glucose $(1.0 \mathrm{~g}, 5.5 \mathrm{mmol})$ was mixed with $n$-dodecanol $(10 \mathrm{~g}, 53 \mathrm{mmol})$ in a $50 \mathrm{~mL}$ round-bottom flask, equipped with a magnetic stirring bar. Then, an acid catalyst (1.8 mol $\%$ of $-\mathrm{SO}_{3} \mathrm{H}$ ) was added and the solution was heated in an oil bath at $393 \mathrm{~K}$ under vacuum $(15 \mathrm{mmHg}$ ) for the desired reaction time. The reaction was monitored by gas chromatography on a Varian 3900 instrument equipped with a flame ionization detector and an HT5 column (30 m x $0.32 \mathrm{~mm} \times 0.25 \mu \mathrm{m})$. Before analysis, AAGs were silylated as described in the supporting information. After complete conversion of glucose, the catalyst was filtered off and the excess $n$ dodecanol was removed under vacuum. For recycling experiments, the solid acid catalyst was 
recovered by filtration at the end of the reaction, washed with ethanol, dried in an oven at $60^{\circ} \mathrm{C}$ and then re-used as is without any further purification. ${ }^{1} \mathrm{H}$ and ${ }^{13} \mathrm{C}$ NMR spectra of the asobtained AAGs are provided in Figures S13 and S14.

\section{Results and discussion}

Sulfonated mesoporous carbons were prepared through a nanocasting method adapted from the procedures of Ryoo [43] and $\mathrm{Wu}$ [44]. Briefly, the experimental protocol involves (i) the preparation of a mesoporous SBA-15 mold, (ii) the impregnation/infiltration of the sacrificial SBA-15 with an aqueous solution of sucrose containing sulfuric acid, (iii) a thermopolymerization reaction at $373 \mathrm{~K}$ and $433 \mathrm{~K}$ followed by a pyrolysis under $\mathrm{N}_{2}$ at a controlled temperature and (iv) the removal of the SBA-15 mold by treatment with $1 \mathrm{M} \mathrm{NaOH}$ in a mixture $\mathrm{H}_{2} \mathrm{O}$ /ethanol (1/1). According to the temperature of pyrolysis, different CMK-3 samples were obtained and referred as CMK-3-T, with $\mathrm{T}$ being the pyrolysis temperature $(723,823,923,1073$ and $1173 \mathrm{~K})$. The as-obtained CMK-3-T mesoporous carbons was then sulfonated by reaction with $\mathrm{ClSO}_{3} \mathrm{H} / \mathrm{H}_{2} \mathrm{SO}_{4}$ at $353 \mathrm{~K}$ for $20 \mathrm{~h}$ affording the CMK-3-T- $\mathrm{SO}_{3} \mathrm{H}$ catalyst. To assess the utility of mesopores in the catalytic experiments, an amorphous carbon, named $\mathrm{AC}-723-\mathrm{SO}_{3} \mathrm{H}$, was prepared in the same way as $\mathrm{CMK}-3-723-\mathrm{SO}_{3} \mathrm{H}$, but without using SBA-15 as hardtemplate. Detailed experimental procedures and full characterization have been placed in the supporting information (Table S1 and figure S1-S10). The textural properties determined by $\mathrm{N}_{2}$ adsorption-desorption and proton exchange capacities determined by treatment with a $\mathrm{KCl}$ solution $\left(\mathrm{H}_{3} \mathrm{O}^{+} / \mathrm{K}^{+}\right.$exchange and titration of released $\left.\mathrm{HCl}\right)$ of all prepared sulfonated carbons are summarized in Table 1. 
Table 1. Characterization of carbon-based materials

\begin{tabular}{|c|c|c|c|c|c|}
\hline Catalyst & $\begin{array}{c}-\mathrm{SO}_{3} \mathrm{H} \\
(\mathrm{mmol} / \mathrm{g}) \\
{[\mathrm{a}]}\end{array}$ & $\begin{array}{l}\mathrm{BET}^{[\mathrm{b}]} \\
\left(\mathrm{m}^{2} / \mathrm{g}\right)\end{array}$ & $\begin{array}{l}\text { Pore diameter } \\
\qquad(\mathrm{nm})^{[\mathrm{c}]}\end{array}$ & $\begin{array}{c}\text { Pore } \\
\text { volume } \\
\left(\mathrm{cm}^{3} / \mathrm{g}\right)^{[\mathrm{d}]}\end{array}$ & $\begin{array}{l}\text { Mesopore } \\
\text { volume } \\
\left(\mathrm{cm}^{3} / \mathrm{g}\right)^{[\mathrm{c}]}\end{array}$ \\
\hline CMK-3-723- $\mathrm{SO}_{3} \mathrm{H}$ & 0.64 & 618 & 3.9 & 0.38 & 0.18 \\
\hline $\mathrm{CMK}-3-823-\mathrm{SO}_{3} \mathrm{H}$ & 0.38 & 800 & 3.6 & 0.68 & 0.48 \\
\hline CMK-3-923- $\mathrm{SO}_{3} \mathrm{H}$ & 0.06 & 790 & 3.8 & 0.64 & 0.51 \\
\hline $\mathrm{CMK}-3-1073-\mathrm{SO}_{3} \mathrm{H}$ & 0 & 777 & 3.7 & 0.75 & 0.72 \\
\hline $\mathrm{CMK}-3-1173-\mathrm{SO}_{3} \mathrm{H}$ & 0 & 983 & 3.7 & 0.74 & 0.70 \\
\hline $\mathrm{AC}-723-\mathrm{SO}_{3} \mathrm{H}$ & 0.54 & 110 & $>50$ & - & - \\
\hline
\end{tabular}

Although high pyrolysis temperatures $(>823 \mathrm{~K}$ ) generated CMK-3-T materials with a welldefined mesoporous structure, it was however not beneficial for the subsequent introduction of sulfonic acid groups in a sufficient amount for catalytic applications (Table 1). As a general trend, the higher the pyrolysis temperature, the lower the $-\mathrm{SO}_{3} \mathrm{H}$ loading, and the higher the mesopority. This result is consistent with previous reports and with our FT-IR, TEM, XRD and $\mathrm{N}_{2}$ adsorption investigations presented in the supporting information. This is actually attributed to a progressive disappearance of sites favorable for the subsequent functionalization of the CMK-3 surface with $-\mathrm{SO}_{3} \mathrm{H}$ groups at high pyrolysis temperature due to a more complete 
carbonization of the precursor forming large carbon sheets which generated, in return, a higher mesoporosity [45]. Hence, for a catalytic application, a compromise has to be made between the amount of $-\mathrm{SO}_{3} \mathrm{H}$ groups and the mesoporosity of the carbon support. Well-ordered carbons are indeed attractive but they bear a negligible amount of $-\mathrm{SO}_{3} \mathrm{H}$ which means that high amount of catalyst should be used in this case, which is, in our views, not realistic for the present application. In this context, only two CMK-3-T-SO${ }_{3} \mathrm{H}$ materials (with $\mathrm{T}=723 \mathrm{~K}$ and $823 \mathrm{~K}$ ) have been selected for catalytic experiments.

In catalytic trials, $1 \mathrm{~g}$ of glucose was mixed with $10 \mathrm{~g}$ of $n$-dodecanol and heated at $120^{\circ} \mathrm{C}$ under vacuum $(15 \mathrm{mmHg})$ in the presence of $1.8 \mathrm{~mol} \%$ of $-\mathrm{SO}_{3} \mathrm{H}$ sites grafted either on CMK-3$\mathrm{T}(\mathrm{T}=723$ and 823$)$ or on AC-723. The reaction was monitored by gas chromatography, allowing the conversion, yields and selectivity to be determined with an experimental error of \pm 5\%. Results are summarized in Table 2. A typical kinetic profile of the reaction is provided in the Figure S11.

Table 2. Optimal results in the catalytic glycosylation of glucose with $n$-dodecanol at $120^{\circ} \mathrm{C}^{\text {a] }}$

\begin{tabular}{|c|c|c|c|c|c|c|c|}
\hline \multirow[b]{2}{*}{ Entry } & \multirow{2}{*}{ Catalyst } & \multirow{2}{*}{$\begin{array}{c}+\mathrm{HO}^{-} \\
\begin{array}{l}\text { Time } \\
\text { (min) }\end{array}\end{array}$} & \multirow[b]{2}{*}{$\begin{array}{c}\text { Conv } \\
(\%)\end{array}$} & \multirow{2}{*}{$\begin{array}{c}\frac{\mathrm{H}^{+}(1.8 \mathrm{~mol} \%), 120^{\circ} \mathrm{C}}{-\mathrm{H}_{2} \mathrm{O}} \\
\mathrm{TOF}\left(\mathrm{h}^{-1}\right)^{[\mathrm{b}]}\end{array}$} & \multicolumn{2}{|c|}{$\begin{array}{c}\text { furanose/pyranose form } \\
(\alpha \text { and } \beta \text { isomers })\end{array}$} & \\
\hline & & & & & $\mathrm{TON}^{[\mathrm{c}]}$ & $\begin{array}{l}\text { Yield } \\
(\%)^{[\mathrm{d}]}\end{array}$ & $\begin{array}{l}\text { Space Time } \\
\text { Yield (kg.m } \\
\left.{ }^{3} \cdot \mathrm{h}^{-1}\right)^{[\mathrm{e}]}\end{array}$ \\
\hline 1 & CMK-3-723 $3^{[\mathrm{e}]}$ & 180 & 86 & $\mathrm{nd}^{[\mathrm{f}]}$ & - & - & - \\
\hline 2 & $\mathrm{CMK}-3-723-\mathrm{SO}_{3} \mathrm{H}$ & 180 & 100 & 110 & 50 & 85 & 48 \\
\hline 3 & $\mathrm{CMK}-3-823-\mathrm{SO}_{3} \mathrm{H}$ & 180 & 100 & 94 & 45 & 82 & 45 \\
\hline 4 & Aquivion PW98 & 180 & 98 & 105 & 53 & 98 & 50 \\
\hline
\end{tabular}




\begin{tabular}{cccccccc}
5 & $\mathrm{SBA}_{-} \mathrm{SO}_{3} \mathrm{H}$ & 600 & 75 & 6 & 0 & 0 & 0 \\
6 & Amberlyst-15 & 540 & 60 & 8.8 & 6 & 10 & 2 \\
7 & $\mathrm{H}-\mathrm{BEA}{ }^{\mathrm{gg}]}$ & 720 & 100 & - & - & 59 & 7 \\
8 & $\mathrm{H}_{2} \mathrm{SO}_{4}$ & 90 & 90 & 118 & 120 & 74 & 86 \\
9 & $\mathrm{AC}^{-723-\mathrm{SO}_{3} \mathrm{H}}$ & 180 & 37 & nd & 4 & 8 & 4 \\
\hline
\end{tabular}

[a] $120^{\circ} \mathrm{C}, 1.8 \mathrm{~mol} \%$ of $-\mathrm{SO}_{3} \mathrm{H}, \mathrm{n}$-dodecanol/glucose mass ratio = 10; [b] determined at a conversion of glucose lower than 20\%; [c] determined at the maximum yield in AAGs; [d] other product are dodecyclpolyglycosides and polydextrose; [e] it corresponds to the mass of product converted per volume of solution and per unit of time (determined from the AAG yield); [f] not determined, only tar-like materials were formed; [g] $15 \mathrm{wt} \%(\mathrm{Si} / \mathrm{Al}=25)$.

Because non-sulfonated CMK-3-T materials (with T=723 K and $823 \mathrm{~K}$ ) bear (only) weak acid sites (-COOH groups), these materials were tested first as control catalysts. Over CMK-3-723, in the above described experimental conditions, $86 \%$ of glucose was converted after $3 \mathrm{~h}$ of reaction, but no formation of AAGs was observed. Only tar-like materials were produced in this case (Table 2, entry 1). Reversely, over CMK-3-723- $\mathrm{SO}_{3} \mathrm{H}$, glucose was completely converted after 3 $\mathrm{h}$ of reaction but AAGs were obtained with $85 \%$ yield, confirming that strong acid sites are required for the glycosylation of glucose with $n$-dodecanol (Table 2, entry 2). Other products formed were dodecylpolyglucosides resulting from the slight oligomerization of glucose on $n$ dodecanol. As determined by gas chromatography, produced AAGs were formed as a mixture of dodecyl glucopyranoside and dodecyl glucofuranoside in a ratio pyranoside/furanoside of 20 . Both forms existed also as two anomers $(\alpha$ and $\beta)$. The $\alpha / \beta$ ratio was 2 for the major dodecyl glucopyranoside form.

The turn over frequency (TOF) and the turn over number (TON) of CMK-3-723-SO $3 \mathrm{H}$ were $110 \mathrm{~h}^{-1}$ and 50, respectively (Table 2, entry 2). Under these conditions, the space time yield reached $48 \mathrm{~kg} \cdot \mathrm{m}^{-3} \cdot \mathrm{h}^{-1}$, which is in line with industrial values of the field. Extrapolation of these results to a reactor of $10 \mathrm{~m}^{3}$, running $8000 \mathrm{~h}$ per year (typical size of reactor in this field of chemistry), suggests a theoretical production capacity of 3840 tons per year and per reactor. It is 
worth noting that $\mathrm{CMK}-3-823-\mathrm{SO}_{3} \mathrm{H}$ afforded similar results, although it was necessary to use a larger amount of catalyst to keep the $-\mathrm{SO}_{3} \mathrm{H}$ mol\% identical in both trials (Table 2, entry 3).

To benchmark CMK-3-723-SO ${ }_{3} \mathrm{H}$, the catalytic performances were further compared under the same conditions to a series of solid acid catalysts previously published in the literature. SBA$\mathrm{SO}_{3} \mathrm{H}$ did not yield AAGs due to its rapid deactivation caused by the stoichiometric release of water (surface hydrolysis and/or $-\mathrm{SO}_{3} \mathrm{H}$ solvation with water, as previously observed [46]), leading to the major thermal degradation of glucose to humins. (Table 2, entry 5). Amberlyst-15, often used in acid-catalyzed reactions, was unfortunately not stable at $120^{\circ} \mathrm{C}$ and it was also quickly degraded in our experimental conditions, leading again to the major formation of tar-like materials (10\% AAG yield at $60 \%$ of conversion of glucose, Table 2, entry 6). In contrast, $\mathrm{H}-$ BEA zeolite afforded AAGs in 59\% yield but with a very low space time yield of $2 \mathrm{~kg} \cdot \mathrm{m}^{-3} \cdot \mathrm{h}^{-1}$ (Table 2, entry 7), which may be rationalized by the presence of acid sites with a lower acid strength than $-\mathrm{SO}_{3} \mathrm{H}$ groups. Interestingly, in terms of catalytic properties, CMK-3-723- $\mathrm{SO}_{3} \mathrm{H}$ was found as performant as Aquivion PFSA PW 98, one of the best solid catalysts reported so far for this reaction (Table 2, entry 4).[27, 28] However, at the end of the reaction, the CMK-3-723$\mathrm{SO}_{3} \mathrm{H}$ has a much lower settling time than Aquivion PFSA, this later being swelled in a very large extent in alkyl alcohol. As a consequence, the recycling procedure of CMK-3-723- $\mathrm{SO}_{3} \mathrm{H}$ was technically much simpler than that of Aquivion PFSA. Recyclability of CMK-3-723- $\mathrm{SO}_{3} \mathrm{H}$ is discussed later in the manuscript. Interestingly, the $\mathrm{CMK}-3-723-\mathrm{SO}_{3} \mathrm{H}$ catalyst has a TOF in a similar range to that of $\mathrm{H}_{2} \mathrm{SO}_{4}$ (Table 1, entry 8). Although the space time yield was lower than the one obtained with $\mathrm{H}_{2} \mathrm{SO}_{4}$, it is noteworthy that the maximum yield of $\mathrm{AAG}$ was higher with CMK-3-723- $\mathrm{SO}_{3} \mathrm{H}(85 \%)$ than with $\mathrm{H}_{2} \mathrm{SO}_{4}(74 \%)$ (Table 1, entries 2 and 8). CMK-3-723-SO $3 \mathrm{H}$ was next compared to $\mathrm{AC}-723-\mathrm{SO}_{3} \mathrm{H}$ in order to highlight the importance of mesopores in the 
catalyst performances. Under identical conditions, $\mathrm{AC}-723-\mathrm{SO}_{3} \mathrm{H}$ was nearly not active achieving a very low yield in AAGs of $8 \%$ after $3 \mathrm{~h}$ of reaction (Table 1, entry 9). Analysis of the used $\mathrm{AC}-723-\mathrm{SO}_{3} \mathrm{H}$ revealed a drastic decrease in the BET surface from 110 to only $3 \mathrm{~m}^{2} / \mathrm{g}$, suggesting the deposition of tar-like materials on the surface of AC-723- $\mathrm{SO}_{3} \mathrm{H}$. In contrast, CMK-3-723- $\mathrm{SO}_{3} \mathrm{H}$ was successfully recycled at least 8 times with only a slight decrease of the AAGs yield from $85 \%$ to $80 \%$ (i.e. within the experimental error) which unambiguously demonstrated the usefulness of mesopores as regards accessibility of $-\mathrm{SO}_{3} \mathrm{H}$ to the reactants and resistance to deactivation (Figure 2).

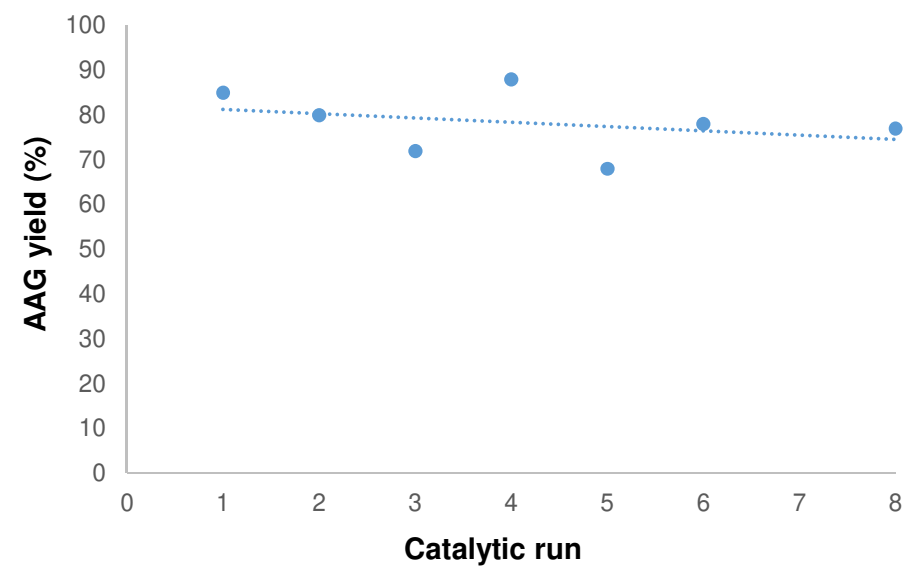

Figure 2. Catalytic recycling of CMK-3-723- $\mathrm{SO}_{3} \mathrm{H}\left(120^{\circ} \mathrm{C}, 1.8 \mathrm{~mol} \%\right.$ of $-\mathrm{SO}_{3} \mathrm{H}, n$-dodecanol/glucose mass ratio = 10; between each cycle, CMK-3-723- $\mathrm{SO}_{3} \mathrm{H}$ was washed with ethanol)

The used CMK-3-723-SO $\mathrm{S}_{3} \mathrm{H}$ (after 1 catalytic cycle) was analyzed by FT-IR and the presence $\mathrm{SO}_{3} \mathrm{H}$ sites was still clearly visible with typical bands between 1000 and $1400 \mathrm{~cm}^{-1}$, as shown in Figure $\mathrm{S} 12$. The determination of the $\mathrm{H}_{3} \mathrm{O}^{+}$exchange capacity showed a slight decrease of the $\mathrm{SO}_{3} \mathrm{H}$ loading from 0.64 to $0.52 \mathrm{mmol} / \mathrm{g}$ which may be explained by (1) a $-\mathrm{SO}_{3} \mathrm{H}$ leaching or (2) a deposition of tar-like materials on the CMK-3-723- $\mathrm{SO}_{3} \mathrm{H}$ surface (i.e. dilution of $-\mathrm{SO}_{3} \mathrm{H}$ ). By 
means of ICP analysis, no trace of sulfur was found into the solution suggesting that the slight decrease in the amount of $-\mathrm{SO}_{3} \mathrm{H}$ sites was presumably due to the partial deposition of tar-like material on the $\mathrm{CMK}-3-723-\mathrm{SO}_{3} \mathrm{H}$ surface. Note that the total inhibition of tar-like materials is nearly impossible to achieve in such reaction and a deactivation of the catalyst will certainly occur in the long term. For instance, the BET surface dropped from 618 to $130 \mathrm{~m}^{2} / \mathrm{g}$ after 8 cycles. However, in contrast to non-mesoporous catalysts, the presence of mesopores seems limiting the deposition of tar-like materials.

To further confirm the absence of $-\mathrm{SO}_{3} \mathrm{H}$ leaching, a hot filtration test was performed. To this end, the CMK-3-723- $\mathrm{SO}_{3} \mathrm{H}$ catalyst was filtered after $20 \%$ conversion and the solution was kept heating at $120^{\circ} \mathrm{C}$. No formation of AAGs was observed after removal of the CMK-3-723-SO $3 \mathrm{H}$ catalyst, thus confirming that, in our case, the catalytic reaction was truly of heterogeneous nature.

The scope of CMK-3-723-SO $\mathrm{S}_{3} \mathrm{H}$ was next generalized to other alkyl alcohol and carbohydrate derivatives (Table 3). Replacing $n$-dodecanol by $n$-hexadecanol had no effect on the catalytic performances of CMK-3-723-SO $3 \mathrm{H}$ and AAGs were obtained in $89 \%$ yield after $180 \mathrm{~min}$ of reaction (Table 3, entry 1). This is an important result since it has been shown that increasing the chain length of AAGs improved their foaming properties and lowered their toxicity, in particular irritability for eyes.[47] From short chain alkyl alcohols such as methanol for instance, the reaction still proceeded well, achieving an AAG yield of $70 \%$ (Table 3, entry 2). Regarding carbohydrates, the substitution of glucose by mannose or galactose in the catalytic glycosylation reaction with $n$-dodecanol was found feasible over $\mathrm{CMK}-3-723-\mathrm{SO}_{3} \mathrm{H}$, but afforded AAGs with a lower yield of $50 \%$ and $30 \%$, respectively, indicating that the reaction conditions initially defined for glucose are not the optimized ones for mannose and galactose (Table 3, entries 3, 4). 
These carbohydrates are indeed known to be more sensitive to the reaction temperature (thermal degradation) than glucose. In this context, the same reaction was conducted from mannose at $100^{\circ} \mathrm{C}$ instead of $120^{\circ} \mathrm{C}$, affording the corresponding AAGs with $95 \%$ yield (Table 3, entry 5).

Table 3. Transposition of the catalytic process to different alkyl alcohols and sugars ${ }^{[\mathrm{a}]}$.

\begin{tabular}{cccccc}
\hline Entry & Sugar & Alkyl alcohol & Time (min) & Conv. (\%) & AAG yield (\%) \\
\hline 1 & Glucose & $n$-hexadecanol & 180 & 100 & 89 \\
$2^{[\mathrm{b}]}$ & Glucose & methanol & 180 & 100 & 70 \\
3 & Mannose & $n$-dodecanol & 60 & 100 & 50 \\
4 & Galactose & $n$-dodecanol & 60 & 66 & 30 \\
$5^{[\mathrm{c}]}$ & Mannose & $n$-dodecanol & 120 & 100 & 95 \\
\hline
\end{tabular}

[a] $120^{\circ} \mathrm{C}, 1.8 \mathrm{~mol} \%$ of $-\mathrm{SO}_{3} \mathrm{H}\left(\mathrm{CMK}-3-723-\mathrm{SO}_{3} \mathrm{H}\right), n$-alkyl alcohol/glucose mass ratio = 10; [b] reaction was performed at reflux of methanol; [c] $100^{\circ} \mathrm{C}$.

\section{Conclusion}

Here, we investigated the catalytic performances, in terms of yield, selectivity, space time yield and recyclability, of $\mathrm{CMK}-3-723-\mathrm{SO}_{3} \mathrm{H}$ and $\mathrm{CMK}-3-823-\mathrm{SO}_{3} \mathrm{H}$ in the Fischer glycosylation of carbohydrates with alkyl alcohols. We were pleased to see that CMK-3-723$\mathrm{SO}_{3} \mathrm{H}$ exhibits catalytic performances superior to the commonly used solid acid catalysts. The presence of mesoporous channels resulted in a high catalyst activity. As a consequence, the catalytic glycosylation rate of carbohydrates with alkyl alcohols was greatly improved, to the detriment of the thermal degradation of carbohydrate which remained drastically limited in this 
case, thus preventing the $\mathrm{CMK}-3-723-\mathrm{SO}_{3} \mathrm{H}$ catalyst from deactivation and allowing its recycling for at least 8 consecutive catalytic cycles. In contrast to Aquivion PFSA, one of the best solid catalyst reported so far for this reaction, $\mathrm{CMK}-3-723-\mathrm{SO}_{3} \mathrm{H}$ has the advantage of being much more easily recovered at the end of the reaction, the recovery of Aquivion PFSA being hampered by its very important swelling leading to a rapid filter clogging. With CMK-3-723-SO $3 \mathrm{H}$, AAGs were obtained with $85-95 \%$ yield while the space time yields of the glycosylation reaction remained in line with those expected at an industrial scale in this field of research. Being able to prepare mesoporous carbons with a high mesoporosity and high $-\mathrm{SO}_{3} \mathrm{H}$ loading represents, in our views, an important perspective to this work to prepare even more performant catalysts.

\section{ASSOCIATED CONTENT}

Supporting Information. Materials, Catalysts preparation, FT-IR characterization, Determination of the $\mathrm{H}_{3} \mathrm{O}^{+}$exchange capacity, $\mathrm{N}_{2}$ adsorption experiments, XRD analysis, TEM analysis, ${ }^{1} \mathrm{H}$ and ${ }^{13} \mathrm{C}$ NMR spectra and kinetic profile of the reaction.

\section{Author Contributions}

The manuscript was written through contributions of all authors. All authors have given approval to the final version of the manuscript.

\section{ACKNOWLEDGMENT}


Authors are grateful to the CNRS, the University of Poitiers and the region Nouvelle Aquitaine for the financial supports. The FR CNRS INCREASE 3707 and the chaire TECHNOGREEN are also strongly acknowledged.

\section{ABBREVIATIONS}

AAG, Amphiphilic alkyl glycosides, PFSA, Perfluorinated sulfonic acid, TOF, Turn over frequency, TON, Turn over number.

\section{References}

[1] A. Corma, S. Iborra, A. Velty, Chem. Rev. 107 (2007) 2411-2502.

[2] P. L. Dhepe, A. Fukuoka, ChemSusChem. 1 (2008) 969-975.

[3] R. Rinaldi, F. Schüth, Ener. Environ. Sci. 2 (2009) 610-626.

[4] M. J. Climent, A. Corma, S. Iborra, Green Chem. 13(2011) 520-540.

[5] S. Van de Vyver, J. Geboers, P. A. Jacobs, B. F. Sels, ChemCatChem. 3(2011) 82-94.

[6] C.-H. Zhou, X. Xia, C.-X. Lin, D.-S.Tong, J. Beltramini, Chem. Soc. Rev. 40 (2011) 55885617.

[7] P. Gallezot, Chem. Soc. Rev. 41 (2012) 1538-1558.

[8] J. Luterbacher, D. M. Alonso, J. Dumesic, Green Chem. 16 (2014) 4816-4838.

[9] M. Yabushita, H. Kobayashi, A. Fukuoka, Appl. Catal. B: Environ.145 (2014) 1-9. 
[10] J. Wang, J. Xi, Y. Wang. Green Chem. 17 (2015) 737-751.

[11] I. Delidovich, P. J. C. Hausoul, L. Deng, R. Pfützenreuter, M. Rose, R. Palkovits, Chem. Rev. 116 (2016) 1540-1599.

[12] J.-P. Lange, Angew. Chem .Int. Ed. 54 (2015) 13186-13197.

[13] J.-P. Lange, Catal. Sci. Technol. 6 (2016) 4759-4767.

[14] F. Jérôme, S. Marinkovic, B. Estrine. ChemSusChem 9 (2018) 1395-1409.

[15] D. Balzer, H. Lüders. In Nonionic surfactants: alkyl polyglucosides, Marcel Dekker: New York and Basel, Switzerland, 2000, vol. 91, p19.

[16] W. von Rybinski, K. Hill. Angew. Chem. Int. Ed. 37 (1998) 1328-1345.

[17] F. Martel, B. Estrine, R. Plantier-Royon, N. Hoffmann, C. Portella, Top. Curr. Chem. 294 (2010) 79-115.

[18] A. Ismail, S. Soultani, M. J. Ghoul, Biotechnol. 69 (1999) 135-143.

[19] A. Ismail, S. Soultani, M. J. Ghoul, Biotechnol. 69 (1999) 145-149.

[20] J. Y. Li, Y. J. Liu, G. Zheng, Y. Sun, Y. N. Hao, T. Fu, Adv. Mater. Res. 550-553 (2012) 75-79.

[21] K. Böge, L. F. Tietze, Fett/Lipid, 100 (1998) S. 36-41.

[22] M. A. Camblor, A. Corma, S. Iborra, S. Miquel, J. Primo, S. Valencia, J. Catal. 172 (1997) 76-84.

[23] N. S. Chaubal, V. Y. Joshi, M. R. J. Sawant, J. Mol. Cat. A: Chem. 267 (2007) 157-164. 
[24] Y. Wu, J. G. Yu, X. F. Ma, J. S. Zhang, Chin. Chem. Let. 18 (2007) 1173-1175.

[25] I. A. Amin, M. A. Yarm, N. I. N. Yusoff, M. Z. Yusoff, A. Ayatillah, Adv. Mater. Res. 620 (2013) 446-452.

[26] A. A. Chaugule, A. R. Jadhav, H. Kim, RSC Adv. 5 (2015) 104715.

[27] A. Karam, K. De Oliveira Vigier, S. Marinkovic, B. Estrine, C. Oldani, F. Jérôme. ACS Catal. 7 (2017) 2990-2997.

[28] (a) A. Karam, K. De Oliveira Vigier, S. Marinkovic, B. Estrine, C. Oldani, F. Jérôme. ChemSusChem, 10 (2017) 3604-3610; (b) W. Deng, M. Liu, Q. Zhang, X. Tan, Y. Wang, Chem. Commun., 46 (2010) 2668-2670; (c) W. Deng, M. Liu, Q. Zhang, X. Tan, Y. Wang, Catal. Today, 164 (2011) 461-466; (d) M. J. Climent, A. Corma, S. Iborra, S. MartinezSilvestre, ChemSusChem, 9 (2016) 3492-3502; (e) W. Deng, M. Liu, Q. Zhang, X. Tan, Y. Wang, Catal. Today, 164 (2011) 461-466; (f) S. Dora, T. Bhaskar, R. Singh, D. V. Naik, D. K. Adhikari, Biores. Technol., 120 (2012), 318-321; (g) N. Villandier, A. Corma, Chem. Commun. 46 (2010), 4408-4410; (h) I. A. Ignatyev, P. G. N. Mertens, C. Van Doorslaer, K. Binnemans, D. E. de Vos, Green Chem. 12 (2010), 1790-1795; (i) A. V. Puga, A. Corma, Chem. Select, 2 (2017) 2495-2498.

[29] N. Villandier, A. Corma, ChemSusChem 4 (2011) 508-513

[30] D. Song, S. BoLu, Y. Guo, J. Leng. Appl. Catal. B. 179 (2015) 445-457.

[31] J. Wang, Z. Zhang, S. Jin, X. Shen. Fuel, 192 (2017) 102-107.

[32] D. Yamaguchi, K. Watanabe, S. Fukumi. Sci. Rep. 6 (2016) 20327. 
[33] W. Yin, Z. Tang, R. H. Venderbosch, Z. Zhang, C. Cannilla, G. Bonura, F. Frusteri, H.J. Heeres. ACS Catal. 6 (2016) 4411-4422.

[34] H. Kobayashi, T. Komanoya, K. Hara, A. Fukuoka. ChemSusChem. 3 (2010) 440-443.

[35] F. Liu, Q. Liu, J. Xu, L. Li, Y.-T. Cui, R. Lang, L. Li, Y. Su, S. Miao, H. Sun, B. Qiao, A. Wang, F. Jerome, T. Zhang. Green. Chem. 2018, DOI: 10.1039/C8GC00039E.

[36] Y. Zhang, A. Wang, T. Zhang. Chem. Commun. 46 (2010) 862-864.

[37] R. Ramakrishnan, T. Sivakumar, D. Arulselvan, K. Sakthivel, E. Elangovan, K. Kathiravan. Appl. Catal. A Gen. 545 (2017) 33-43.

[38] F. Liu, K. Huang, A. Zheng, F.-S. Xiao, S. Dai, ACS Catal. 8 (2018) 372-391.

[39] (a) R. Zhong, Y. Liao, L. Peng, R. I. Iacobescu, Y. Pontikes, R. Shu, L. Ma, B. F. Sels, ACS Sustainable Chem. Eng. 6 (2018) 7859-7870; (b) D. S. Sheng Su, S. Perathoner, G. Centi. Chem. Rev. 113 (2013) 5782-5816.

[40] R. Zhong, F. Yu, W. Schutyser, Y. Liao, F. de Clippel, L. Peng, B. F. Sels, Appl. Catal. B Environ. 206 (2017) 74-88.

[41] R. Zhong, B. F. Sels, Appl. Catal. B Environ. 236 (2018) 518-545.

[42] E. Doustkhah, J. Lin, S. Rostamnia, C. Len, R. Luque, X. Luo, Y. Bando, K. C.-W. Wu, J. Kim, Y. Yamauchi, Y. Ide, Chem. Eur. J. (2018), in press https://doiorg.inc.bib.cnrs.fr/10.1002/chem.201802183

[43]. S. Jun, S. H. Joo, R. Ryoo, M. Kruk, M. Jaroniec, Z. Liu, T. Ohsuna, O. Terasaki, J. Am. Chem. Soc., 122 (2000), 10712-10713 
[44] R Xing, Y. Liu, Y. Wang, L. Chen, H. Wu, Y. Jiang, M. He, P. Wu, Micropor. Mesopor. Mater. 105 (2007) 41-48.

[45] M. Zhang, A. Sun, Y. Meng, L. Wang, H. Jiang, G. Li., Micropor. Mesopor. Mater., 204 (2015), 210-217.

[46] A. Karam, J.-C. Alonso, T. Gerganova, P. Ferreira, N. Bion, J. Barrault, F. Jerome, Chem. Commun. 45 (2009) 7000-7002.

[47] A. Mehling, M. Kleber, H. Hensen. Food Chem Toxicol.45 (2007) 747-758.

BRIEFS Sulfonated mesoposous carbons efficiently catalyze the glycosylation of various monosaccharides with alkyl alcohols.

\section{TABLE OF CONTENT}

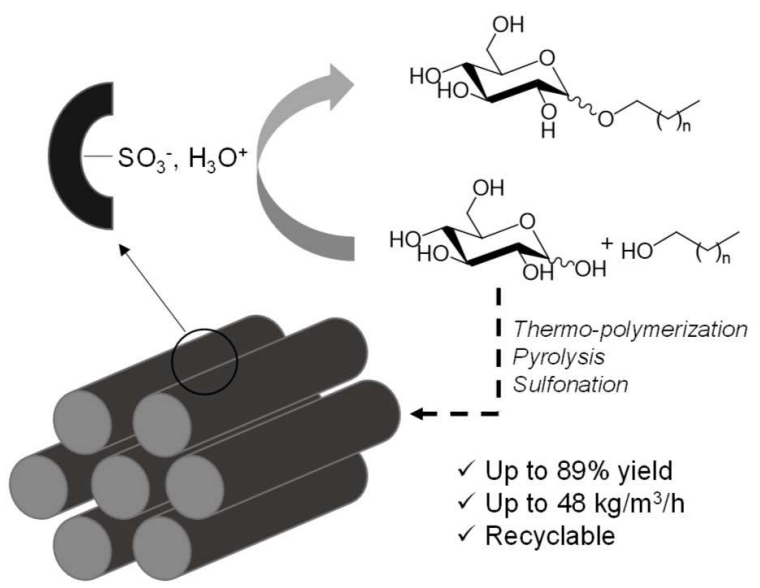

Sulfonated mesoporous carbons 
BRIEFS Sulfonated mesoposous carbons efficiently catalyze the glycosylation of various monosaccharides with alkyl alcohols.

\section{TABLE OF CONTENT}

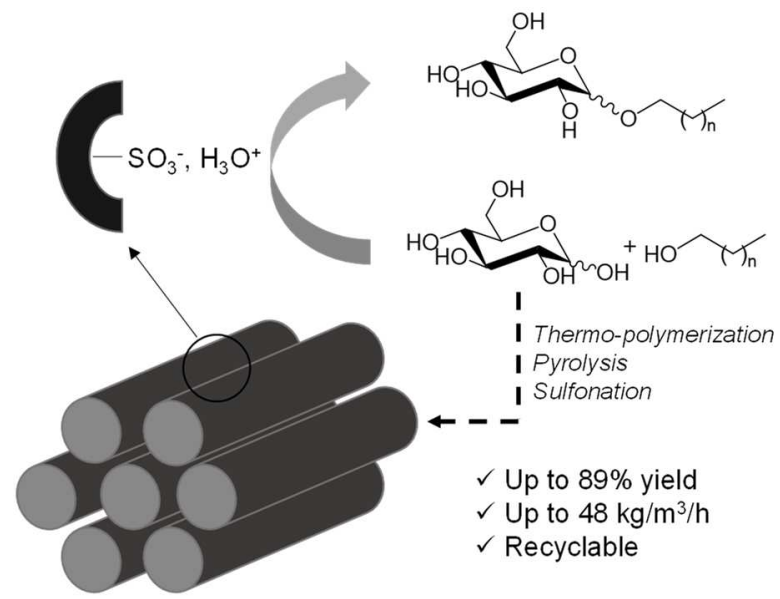

Sulfonated mesoporous

carbons 